\title{
Análise relacional do Programa Nacional de Alimentação Escolar: relevando dimensões institucionais dos processos locais de implementação
}

\author{
Alan Ferreira de Freitas* \\ Alair Ferreira de Freitas**
}

Resumo: Este trabalho procurou elucidar uma dimensão institucional de análise da implementação do Programa Nacional de Alimentação Escolar (Pnae). A pesquisa foi de caráter interpretativo e descritivo, de abordagem qualitativa, e utilizou como estratégia o estudo dos casos dos municípios de Espera Feliz e Guaraciaba, estado de Minas Gerais. A pesquisa confirmou a tese de que as interações entre diferentes atores no processo de implementação do Pnae produz efeitos sobre o comportamento desses atores e, mais especificamente, permite a construção de regras que constrangem e habilitam suas ações, produzindo novos padrões de interações e condicionando a forma como o programa é implementado localmente. A análise institucional também revela que as interações entre os atores e o "jogo da implementação" implicam em mudanças institucionais que são inerentes à tentativa de aproximar o programa à realidade local.

Palavras-Chave: Politicas Públicas. Instituições. Interações. Agricultura familiar. Cooperativas.

\section{Relational analysis of the Brazilian School Nutrition Program: releving institutional dimensions of local implementation processes}

Abstract: This paper sought to elucidate an institutional dimension of analysis of the implementation of the Brazilian School Nutrition Program (Pnae). The research was interpretative and descriptive, with a qualitative approach, and used as a strategy the study of cases of the municipalities of Espera Feliz and Guaraciaba, Minas Gerais state. The research confirmed the thesis that interactions between different actors in the Pnae implementation process produces effects on the behavior of these actors and, more specifically, allows the construction of rules that constrain and enable their actions, producing new patterns of interactions and conditioning the way the program is implemented locally. Institutional analysis also reveals that interactions between actors and the "implementation game" imply institutional changes that are inherent in the attempt to bring the program closer to local reality.

Keywords: Public policies. Institutions. Interactions. Family farming. Cooperatives.
Recebido: 04.09.19 Aprovado: 23.03.20

\footnotetext{
* Alan Ferreira de Freitas é doutor em extensão rural pela Universidade Federal de Viçosa (UFV), professor adjunto do Departamento de Administração e Contabilidade e orientador permanente do Programa de PósGraduação em Administração da Universidade Federal de Viçosa (UFV), Viçosa, Minas Gerais, Brasil.

Orcid: 0000-00025952-2546. <alanf.freitas@ufv. br>.

** Alair Ferreira de Freitas é doutor em administração pela Universidade Federal de Minas Gerais (UFMG), professor adjunto do Departamento de Economia Rural da Universidade Federal de Viçosa (UFV) e orientador permanente do Programa de PósGraduação em Extensão Rural da Universidade Federal de Viçosa (UFV),
} 
Viçosa, Minas Gerais, Brasil.

Orcid: 0000-0001 6770-6030.

<alair.freitas@ufv. br>.

1. Considerando institucionalidades como normas e regras que conduzem os comportamentos em contextos específicos. As dinâmicas locais dos agricultores referem se à forma como se organizam, produzem e interagem e, assim configuram também institucionalidades.

\section{Introdução}

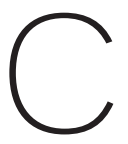

om a promulgação da Lei 11.947 de 2009, o Programa Nacional de Alimentação Escolar (Pnae) passou por mudanças no formato das compras públicas de alimentos destinados à alimentação escolar. Tal lei exige que no mínimo $30 \%$ dos recursos sejam gastos com a aquisição de gêneros alimentícios oriundos da agricultura familiar local. A reformulação do Pnae provocou mudanças em seu processo de implementação e representou um grande avanço nas políticas públicas para a agricultura familiar ao focar no processo de comercialização.

Para Cátia Grisa (2012) e Kate Abreu (2014), a concretização da venda dos alimentos da agricultura familiar às escolas exige dos agricultores familiares a adequação a normas sanitárias, a regularidade das entregas, a organização social, bem como a criação de relações com as entidades e unidades executoras e outras organizações locais que apoiam esse processo. Neste caso, mais que simplesmente executar o que determina a lei, a implementação das compras públicas perpassa a interação entre diferentes atores locais objetivando a efetividade das disposições legais e viabilidade desse circuito de abastecimento alimentar. Essas constatações indicam que a Lei 11.947/2009 implicou em novas institucionalidades à execução do Pnae, as quais interagem com as dinâmicas locais ${ }^{1}$, criando, adequando e modificando comportamentos, formas de interação e, assim, instituições. Formuladores de políticas públicas podem definir os dispositivos regulatórios centrais de uma determinada política, mas não definem a forma como localmente eles são traduzidos e como novas regras - formais ou informais - são criadas e influenciam a política, particularizando sua operacionalização e trajetória institucional.

No caso do Pnae, as regras gerais de acesso e funcionamento são definidas pelo Estado, que delimita o desenho institucional do programa, pois é o único comprador. Essa forma preestabelecida induz os processos de negociação e a criação de dispositivos - regras - que condicionam as transações e as relações de modo a tornar o processo adequado à realidade dos agricultores familiares e dos governos locais. Porém, a partir do contexto local e dos atores que o constituem, podem surgir novas regras e procedimentos, os quais geram novas oportunidades e constrangimentos que, de formas distintas, causarão impacto no comportamento dos atores envolvidos e na forma como operam a política pública localmente (Rocha, 2004). Isso quer dizer que a implementação de uma política pública, tendo em vista os arranjos institucionais por ela trazidos, representará a adaptação ou a substituição de instituições anteriormente vigentes.

Essas constatações mantêm consonância com os resultados das pesquisas de Gabriela Lotta (2010), Eduardo Marques (2003) e Marcelo Silva e Cláudia Schmitt 
(2010), cujas conclusões revelam que os efeitos das políticas públicas se diferenciam conforme o contexto de implementação, pois as regras gerais passam por adaptações aos contextos locais. Parafraseando Silva e Schmitt (2010), as políticas públicas não são simplesmente implementadas, mas também interpretadas, adaptadas e adequadas às realidades sociais e culturais locais. Estes argumentos fundamentam a premissa de que a implementação de políticas públicas não deve ser analisada apenas por uma ótica normativa, precisa ser edificada sobre abordagens relacionais, considerando as interações sociais, mais ou menos institucionalizadas, entre os atores locais e o modo como eles se apropriam e operam as regras que orientam a política.

Esse posicionamento fundamentado na literatura especializada nos permite defender a tese de que as interações entre diferentes atores no processo de implementação produz efeitos sobre o comportamento desses atores, por meio da construção de significados e regras que os orientam, produzindo novos padrões de interações e condicionando a forma como a política é operada localmente. Para operacionalizar empiricamente esta tese e elucidar esse problema de pesquisa, foram estudados a implementação do Pnae no município de Espera Feliz, por meio da Cooperativa da Agricultura familiar de Espera Feliz (Coofeliz), e em Guaraciaba, da Associação dos Agricultores Familiares de Guaraciaba (Asfag), organizações que em seus municípios protagonizam a venda de alimentos da agricultura familiar para a alimentação escolar.

Procura-se entender o que os casos de Espera Feliz e Guaraciaba podem revelar sobre os dispositivos institucionais criados localmente para facilitar - ou constranger o processo de compra e venda de alimentos para as escolas públicas e como o acesso ao Pnae tem provocado mudanças institucionais que interferem nas práticas e relações dos atores envolvidos. Esses casos são muito diferentes entre si e emblemáticos sobre as experiências de execução do programa, conformando importante base empírica para lastrear a abordagem relacional que aqui se empreende, referenciada por uma análise institucional do processo de implementação da política pública.

\section{Orientações normativas da operacionalização do Pnae}

A resolução Fundo Nacional de Desenvolvimento da Educação (FNDE) n. .26 de 2013 define que podem fornecer produtos para o Pnae os grupos formais com Declarações de Aptidão (DAP) $)^{2}$ jurídicas, grupos de agricultores não organizados formalmente e agricultores individuais, tendo um limite individual de venda de no máximo R\$ 20 mil por DAP/ano. Os consumidores, ou seja, os compradores, são as

\footnotetext{
2. As Declarações de Aptidão ao Programa Nacional de Fortalecimento da Agricultura Familiar (Pronaf), são uma espécie de identidade que comprova que o agricultor ou a agricultora é familiar. Tal declaração é emitida, principalmente, pelos órgãos de extensão rural locais ou sindicatos de trabalhadores rurais. No caso das DAPs Jurídicas, são declarações que atestam que a organização formal, com CNPJ, é vinculada a agricultura familiar, para isso é necessário que no mínimo $70 \%$ dos cooperados ou associados possuam DAPs individuais.
} 
Entidades Executoras (E.Ex), aquelas instituições que integram as redes públicas de ensino federal, estadual e municipal, que recebem recursos diretamente do FNDE. As secretarias estaduais de educação, as secretarias municipais de educação e as escolas federais são as E.Ex. Existem também as Entidades Articuladoras (EA), que são entidades representativas da agricultura familiar, cadastradas no Sistema Brasileiro de Assistência Técnica e Extensão Rural (Sibrater), Sindicato de Trabalhadores Rurais e de Trabalhadores da Agricultura Familiar (Sintraf) e entidades credenciadas pelo governo federal para emissão da DAP. Essas entidades podem assumir a responsabilidade de articular e assessorar os agricultores em relação ao processo de venda.

De acordo com a resolução que regulamenta o funcionamento da compra, os agricultores familiares precisam construir um projeto de venda. No projeto deve estar especificado o nome do proponente, os fornecedores - agricultores - e os produtos, discriminando unidade, quantidade e preço, bem como os valores totais. 0 projeto de venda é sempre submetido a partir da chamada pública elaborada pela E.Ex. Após a chamada pública, há a seleção dos projetos de venda se houver mais de um, em seguida a assinatura do contrato e depois a comprovação da entrega dos produtos e os recebimentos dos valores vendidos por parte dos agricultores.

Segundo documentos de orientação do FNDE, o primeiro passo para que a entrega aconteça está relacionado à articulação dos atores sociais e ao mapeamento dos produtos e produtores da agricultura familiar. Neste caso, a Secretaria de Educação deve solicitar à Secretaria de Agricultura, à empresa de extensão rural e ao Sindicato dos Trabalhadores Rurais, quando houver, um mapeamento conjunto dos produtos da agricultura familiar local a fim de analisar as vocações produtivas. Após o mapeamento dos produtos da agricultura familiar, os cardápios da alimentação escolar deverão ser elaborados pelo nutricionista responsável (Brasil, 2014).

Definido o cardápio, define-se o preço dos produtos. De acordo com a resolução $n$. . 26, o preço de aquisição será o preço médio pesquisado por, no mínimo, três mercados locais, priorizando as feiras livre ou as feiras da agricultura familiar, quando houver. Quando existir, comprovadamente, produtos orgânicos, pode-se acrescer o preço de tais alimentos em até $30 \%$ do valor sobre os produtos convencionais. Cumprida a etapa de precificação, os editais das chamadas públicas devem ser divulgados em jornal de circulação local ou regional e na forma de mural em local público de ampla circulação. Precisam indicar quais os alimentos e a quantidade de cada um deles que desejam adquirir da agricultura familiar para a alimentação escolar e deverão permanecer abertos para recebimento dos projetos de venda por um período mínimo de 20 dias. Vale ressaltar que a E.Ex pode acrescer em edital sua preferência em receber projeto apenas de DAPs jurídicas. 
Após esta etapa de seleção das propostas, com os projetos de venda selecionados, acontece a assinatura do contrato fornecido pela E.Ex. No contrato estão determinados prazos. Os prazos podem ser uma construção e um acordo entre os atores envolvidos, respeitando o estabelecido pelos agricultores e as demandas das escolas. Quando o produto é entregue na escola o representante da entidade executora e do grupo fornecedor deverá assinar o Termo de Recebimento da Agricultura Familiar, garantindo formalmente que houve a entrega e dando base para o pagamento. Esses procedimentos mostram que há delimitações de um fluxo processual para que ocorra a compra dos produtos, e para que ele aconteça existem regras delimitadas e muitos acordos - formais e informais - a serem construídos.

\section{Abordagem relacional à implementação de políticas públicas: as instituições importam?}

Abordagem relacional aqui diz respeito a um ângulo de análise que privilegia as relações sociais, ou seja, as interações entre os atores no processo de implementação das políticas públicas. Implica ressaltar, pois, que a ação dos indivíduos é sempre contextualizada por um ambiente institucional, influenciando-o e sendo por ele influenciada. Esse caráter recursivo entre estruturas sociais e ação evidencia, no lastro de nosso objeto de estudo, que a implementação das políticas públicas é condicionada pelo aparato legal e normativo, mas também pela forma como os atores locais a compreendem e se relacionam para acessá-la. A abordagem relacional, portanto, edifica-se sobre pressupostos institucionalistas, de base sociológica, tentando evidenciar processos sociais e mecanismos institucionais que modelam a trajetória local de determinada política pública.

Para Marta Arretche (2007), existem vários motivos que justificam um olhar institucional sobre a implementação de políticas públicas. O primeiro é que as políticas públicas não são formuladas ou implementadas pelos atores sociais em um vazio institucional. Existem significados, regras e práticas formais e informais que estruturam e condicionam as escolhas dos atores, o que interfere na dinâmica de implementação. No caso do Pnae, as regras estruturadas pelo governo federal e aquelas criadas localmente pelos próprios atores vão interferir no formato estabelecido para colocar em prática a compra de alimentos da agricultura familiar. Isso quer dizer que a política pode ser afetada por regras mais gerais e exógenas ao lócus de implementação, como por regras mais específicas do poder público local e outras edificadas sob a interação dos atores. A abordagem institucional também pode contribuir ao revelar que a posição dos atores nas redes e nas organizações pode influenciar a formação de suas preferências e guiar a forma como se relacionam e, assim, alterar a trajetória local das políticas públicas. 
Portanto, para se compreender os rumos e os resultados das políticas é importante considerar seus condicionantes institucionais, o que reforça a premissa de que as instituições importam. Douglas North (1990) considera que instituições consistem, sobretudo, de regras informais e formais. As informais se pautam na informação transmitida e comunicada socialmente, como parte da dimensão cultural, que define a forma como os indivíduos processam e utilizam a informação. As regras formais são aquelas constituídas legalmente, ou seja, apresentam caráter jurídico e emergem do complexo processo de organização social com o objetivo de ordenar e coordenar a ação coletiva.

As instituições podem, então, ser ainda definidas como dispositivos cognitivos que estruturam e canalizam as ações individuais, fornecendo aos atores os recursos e os limites constitutivos da formação das preferências individuais. Desta forma, as instituições são modelos de referência que criam rotinas e hábitos que orientam a ação humana. Quando falamos dos processos econômicos, as instituições importam para dar estabilidade ao processo, tendo poder coercitivo sobre ações que fujam dos padrões (Dimaggio \& Powell, 2005).

Desta forma, as instituições constrangem ou habilitam a ação por meio de dispositivos que podem ser informais - tabus, costumes, regras morais etc. - ou formais - leis, decretos, constituições etc. As restrições indicam que os indivíduos possuem constrangimentos às suas ações e escolhas, pois as instituições impõem determinadas formas de conduta (Pearson, 2004). Essas definições estão alinhadas com as de William Scott (1995), que concebe as instituições como estruturas e atividades cognitivas, normativas e reguladoras que provêm estabilidade e significado ao comportamento social. Assim, para este estudo vamos considerar instituições como qualquer regra ou forma de condicionamento coletivo, que moldam as interações humanas em determinados grupos sociais.

A introdução desse enfoque na abordagem institucional nesta pesquisa foi essencial para elucidar a ação dos atores, bem como as criações e a modificação das regras para a operacionalização do Pnae nos municípios estudados. Os atores envolvidos nesse processo não são considerados meros expectadores, mas agentes capazes de influenciar agendas públicas. E as respostas das organizações em termos de adaptação às exigências - e contingências - das políticas públicas não são mecânicas ou homogêneas, dependem de características particulares de cada entidade, o que vai conformar diferentes estilos, tempos e intensidades de mudanças (Silva \& Schmitt, 2010).

A abordagem da análise institucional - fundada no neoinstitucionalismo - ganhou destaque nas ciências políticas e nos estudos organizacionais, buscando elucidar 
a importância das instituições para a análise das formas de ação do Estado. Para além do pressuposto geral de que "as instituições importam", a relevância está em identificar quais instituições afetam comportamentos individuais e coletivos e como essas instituições operam e resistem, ou seja, por meio de que processos e mecanismos exercem influência sobre as decisões políticas e se reproduzem ao longo do tempo (Hall \& Taylor, 2003).

Para o neoinstitucionalismo sociológico, as instituições são concebidas não só como regras, procedimentos ou normas formais, mas também

como os sistemas de símbolos, os esquemas cognitivos e os modelos morais que fornecem padrões e guiam a ação humana (Hall \& Taylor, 2003: 209).

Estruturas cognitivas condicionam e são condicionadas pelas relações entre atores sociais mediante o compartilhamento de significados, ou seja, pela intersubjetividade que se estabelece entre eles. Neste caso, a ação está intrinsecamente relacionada às interpretações. Seria dizer que as organizações adotam novas práticas institucionais porque estas garantem maior legitimidade social, ou seja, adotam a prática porque possuem reconhecimento dentro de um ambiente cultural mais amplo. As novas práticas dotam de significado as ações dos atores. Mas como surgem essas novas práticas? Como as mudanças institucionais ocorrem?

Há consenso, entre as correntes do neoinstitucionalismo, de que todas as instituições surgem e se modificam em função da atuação de indivíduos e da interação entre eles. No entanto, a intervenção individual não é isenta e autônoma. Ela se insere em um contexto social e político específico e quase sempre se manifesta de forma complexa, mediante uma longa e complicada cadeia de interações e em decorrência de uma série de eventos nem sempre intencionais ou adequadamente previstos. Sendo produto das interações dos atores, as regras devem ser construídas e/ou alteradas como parte da dinâmica relacional entre atores. Isso quer dizer que as instituições são modificadas pelos indivíduos quando estes interagem uns com os outros (Klijn, 1996). As mudanças institucionais, assim, são modificações nos pensamentos e comportamentos dos indivíduos (Scott, 1995).

Isso quer dizer que as mudanças institucionais estão relacionadas às mudanças nas relações sociais. Poderíamos compreender, dessa forma, que quando se passa a operacionalizar a compra de produtos da agricultura familiar para a alimentação escolar, as regras são interpretadas pelo grupo, moldando as relações, assim como são moldados por elas, a partir das interpretações que fazem (Pearson, 2004). 
Charles Kirschbaum (2010) apresentou uma visão relacional da construção das instituições. O autor afirma que existe um processo de negociação, em vários níveis, que caracteriza a indução de padrões de interação entre grupos de uma organização ou entre organizações pelo ambiente institucional. A construção e transformação dos laços sociais seriam a base da difusão e tradução de práticas e regras por uma organização ou entre organizações. De acordo com o autor, podemos entender que a implementação de uma política pública perpassa por um processo de negociação e interação, que leva em consideração as regras impostas e as formas de organização exigida. Nessa direção, para Alair Freitas (2015), o resultado das políticas pode ser condicionado pela maneira como os atores negociam seu acesso a elas e sua permanência no processo de implementação.

\section{Metodologia}

Esta pesquisa foi caracterizada como descritiva de abordagem interpretativa e com natureza qualitativa. A dimensão empírica deste trabalho se ateve aos casos dos municípios mineiros de Espera Feliz e Guaraciaba, localizados na Zona da Mata de Minas Gerais. Não se trata de uma comparação, mas de ampliar o universo empírico e permitir maior amplitude às constatações da pesquisa. Os casos foram escolhidos pela grande presença de DAPs ao Pronaf nos dois municípios, o que habilita os agricultores a acessarem programas do governo. Além disso, os municípios contam com predominância de população rural e expressividade de organizações coletivas de agricultores familiares.

De acordo com o Instituto Brasileiro de Geografia e Estatística (IBGE, 2010), Guaraciaba possui uma população de 10.532 habitantes, sendo cerca de $70 \%$ da população residente em área rural. Guaraciaba conta com 1.044 DAPs, e 794 delas encontram-se ativas. No município, a grande particularidade é o número de associações comunitárias rurais, visto que praticamente todas as comunidades rurais possuem uma associação constituída. De acordo com constatações da pesquisa de campo, são nove associações, e os relatos indicaram que apenas cinco apresentam DAP jurídica. No entanto, é por meio da Associação dos Agricultores Familiares de Guaraciaba (Asfag) que ocorre as vendas dos produtos por meio do Pnae. A Asfag foi uma associação criada em 2005 para congregar associados de todas as outras associações e é reconhecida como "associação geral" ou "associação central". Até o ano de 2017 a associação contava com 57 associados.

Por sua vez, Espera Feliz, em 2016, era considerado o município de Minas Gerais com maior número de DAPs, sendo 2.223 e um total de 1.639 DAPs ativas. Segundo Censo demográfico de 2010, o município possuía 22.856 habitantes, sendo 8.682 
habitantes de áreas rurais. A Cooperativa da Agricultura Familiar Solidária de Espera Feliz (Coofeliz) foi constituída em 2006 e em 2017 contava com 93 cooperados, 60 deles envolvidos com o fornecimento de produtos para a alimentação escolar. Coofeliz e Asfag foram selecionadas para a pesquisa por serem as organizações com DAP jurídica nesses municípios que operacionalizam a venda dos produtos da agricultura familiar para o Pnae. Foram entrevistados os diretores da Coofeliz e da Asfag bem como agricultores familiares vinculados a essas organizações.

As entrevistas nos municípios ocorreram entre outubro de 2016 a março de 2017. Como o objetivo era captar as relações das organizações formais com outros atores e não as experiências individuais de produção e entrega dos agricultores, utilizou-se o critério da saturação proposto por Gil (2010). Além da indicação, também se levou em consideração a disponibilidade dos informantes e as condições de acesso aos mesmos. No total, foram realizadas entrevistas com 27 informantes. Foram realizadas 14 entrevistas no município de Guaraciaba, sendo oito com agricultores familiares, quatro com representantes do poder público, uma com técnico da Empresa de Assistência Técnica e Extensão Rural (Emater) e uma com representante do Sindicato dos Trabalhadores Rurais (STR). Em Espera Feliz, foram realizadas 13 entrevistas, sendo oito com agricultores familiares, além de uma com representante do STR, uma com representante do Pode Público, uma com técnico da Emater e uma com técnico do Centro de Tecnologias Alternativas. No corpo do texto, os informantes da pesquisa serão referenciados com a denominação "agricultor familiar", "poder público" e "entidade parceira". Para diferenciar os informantes da mesma denominação foi realizada uma identificação numérica, ficando como exemplo "agricultor familiar 1; agricultor familiar 2 etc.

Para analisar os dados, foram realizados os tratamentos das comunicações gravadas. Para isso, utilizou-se a técnica chamada de análise de conteúdo, segundo Christian Laville e Jean Dionne (1999). Ao seguir a sugestão dos autores, a análise se dividiu em três etapas: o recorte de conteúdos, a definição das categorias e a categorização final das unidades de análise. Os conteúdos analisados foram agrupados de acordo com sua importância perante a tese defendida e posteriormente foram alocados conforme as categorias definidas, quais sejam:

$$
\begin{aligned}
& \text { i. a operacionalização do Pnae; } \\
& \text { ii. as regras criadas; e } \\
& \text { iii. as mudanças institucionais. }
\end{aligned}
$$

A divisão por categorias ajudou na compreensão dos dados e facilitou a interpretação e a escrita. 


\section{Resultados e discussão}

Todas as etapas e os procedimentos da compra de alimentos da agricultura familiar pelo Estado estão delimitados pela Resolução CD/ FNDE n. 26, de 17 de junho de 2013, que dispõe sobre o atendimento da alimentação escolar aos alunos da educação básica no âmbito do Pnae. Nessa resolução estão descritos os atores envolvidos e os papéis que assumem na implementação da política, buscando, com este "roteiro normativo", orientar todos os processos e estabilizar as relações no interior do programa.

Apesar dos aspectos normativos delimitados previamente pelo Estado, este trabaIho procurou investigar a trajetória de interação dos agricultores com as normas do programa e as normas que eles próprios foram criando para atender as exigências, e como novas regras eram produzidas a partir da interação entre os diferentes atores implementadores do Pnae.

\section{A construção social das regras de implementação \\ O caso de Espera Feliz e a edificação de mecanismos sociais de controle}

As organizações da agricultura familiar em Espera Feliz começaram a se estruturar na década de 1980, principalmente a partir do movimento da Igreja católica, que desenvolvia um trabalho pastoral baseado nas comunidades rurais. Para Márcio Silva (2010), o Sindicato dos Trabalhadores Rurais (STR) de Espera Feliz surgiu neste contexto. Com a atuação do STR na organização social comunitária e luta por direitos, novas organizações emergiram para satisfazer as necessidades econômicas dos agricultores. Foram constituídas ao longo dos anos no âmbito dos grupos vinculados ao STR a Associação Intermunicipal da Agricultura Familiar (Asimaf), que depois deu origem à Cooperativa de Produção da Agricultura Familiar (Coofeliz), e a Cooperativa de Crédito Solidário (Cresol), além de outras organizações vinculadas a jovens rurais e a grupos de mulheres.

De acordo com a presidente da Coofeliz, o Pnae se tornou o principal canal de comercialização dos produtos da agricultura familiar do município. Antes de 2009, a administração pública local adquiria a produção para a merenda escolar de grandes atacadistas. Com a Lei 11.947, começaram as articulações para que houvesse a compra dos agricultores organizados. Sobre o "programa dos 30\%" ou da "merenda escolar", como é conhecido o Pnae pelos agricultores entrevistados, as negociações 
foram encetadas da própria Coofeliz, que contatou a Secretaria Municipal de Educação. A diretoria da Coofeliz realizou reuniões com a Secretaria de Educação para visualizar a venda e definir localmente as atribuições do poder público e da cooperativa, iniciando aí um processo de tradução da política e de negociação sobre as condições de sua operacionalização em Espera Feliz.

Dispositivos institucionais na compra

de produtos da agricultura familiar para a alimentação escolar

Antes de vender produtos agrícolas para a merenda escolar, os agricultores entrevistados em Espera Feliz salientaram que o faziam até então por meio de atravessadores e nas feiras locais, privilegiando circuitos curtos de comercialização. A comercialização via Pnae significou um avanço nas oportunidades de ampliar a venda de produtos agroecológicos.

A experiência com o Programa de Aquisição de Alimentos - que também é um programa de compra institucional de alimentos da agricultura familiar - se revelou como importante na consolidação posterior da forma de comercialização com as escolas pelo Pnae. A trajetória de articulação para a venda foi um passo histórico determinante. Esse pressuposto corrobora que a trajetória histórica das organizações de agricultores familiares vai influencia em sua capacidade de operar o Pnae. Para Hall e Taylor (2003), a dependência do caminho é uma causalidade social que depende da trajetória percorrida, ou seja, é a influência de eventos anteriores nos resultados e nas trajetórias.

Em Espera Feliz, outra trajetória que importa é a inserção dos agricultores familiares locais nos movimentos católicos dos anos 1980 como o Movimento da Boa Nova (Mobom) e as Comunidades Eclesiais de Base (CEBs). A inserção nesses grupos promoveu o adensamento das relações sociais por meio da fé, da espiritualidade e da solidariedade, princípios da organização social. O Centro de Tecnologias Alternativas da Zona da Mata (CTA-ZM) também tem um peso histórico em Espera Feliz ao ser um articulador e difusor da agroecologia e da agricultora ecológica. Inseridos em diversas iniciativas, os agricultores se organizavam e criavam sua identidade coletiva com os preceitos da cooperação e da sustentabilidade (Freitas, 2015).

Para ser operada localmente, a compra institucional via Pnae e os processos que a sustentam passaram por adequações e se institucionalizaram. Segundo relatos dos agricultores ligados a diretoria da Coofeliz, algumas ações e regras criadas pelos agricultores são por eles consideradas "estratégias Xeque-Mate". O termo foi usado metaforicamente pela diretoria da cooperativa para fazer menção à importância da 
ação desenvolvida pela organização. Seria basicamente ações positivas implementadas pelos agricultores, compreendidas como determinantes para a efetividade da participação da agricultura familiar na implementação da política. Nos termos de nossa reflexão podemos definir aqui como dispositivos institucionais construídos pelos agricultores para facilitar sua inserção na compra institucional e superar as barreiras que ela impõe. Essas "estratégias" revelam a criação e/ou transformação de dispositivos institucionais, pois dizem respeito a regras que a cooperativa ajudou a construir, assumindo protagonismo na mobilização do processo e na elaboração de acordos com a prefeitura.

Ante os desafios iniciais de colocar na alimentação escolar os produtos locais e sazonais, a Coofeliz, em parceria com o STR e o CTA, promoveu seminários com as cozinheiras e diretoras das escolas municipais, no intuito de mostrar a qualidade dos produtos agroecológicos. Os relatos do Agricultor 3 descrevem essa questão:

\begin{abstract}
Eu lembro até no início que começou a trabalhar com a merenda escolar que a gente fez os seminários com as merendeiras, deu certificado e tudo mais, com essa ideia de saber, por exemplo, que o produto que os agricultores daqui entregam não necessariamente tem o mesmo formato e beleza dos que são produzidos com veneno. Vai uma cenoura menor, vai uma batata menor uma coisa assim, mas que dá pra fazer outras coisas sem ser aquilo que elas têm (Depoimento Agricultor familiar 3).
\end{abstract}

Essa estratégia local se tornou importante para mudar as representações sociais das cozinheiras das escolas em relação a noção de qualidade dos produtos, questão essencial para promover a aceitação dos produtos locais. Além disso, foram realizadas receitas com o aproveitamento dos produtos da agricultura familiar, de modo a não haver mais resistência na aceitação, uma vez que há diferenças na aparência (tamanho e cor, por exemplo) entre alguns produtos locais e os encontrados nos supermercados. Ademais, ocorreram encontros com professoras e gestores da secretaria de educação para tratar de segurança alimentar e dos benefícios dos alimentos sem agrotóxico. Essas ações trouxeram maior legitimidade à produção local sem agrotóxico, facilitando a aceitação dos produtos.

Neste sentido, as mudanças institucionais que possibilitaram o acesso e o protagonismo da agricultura familiar no Pnae em Espera Feliz se iniciam por um processo cognitivo, ressaltando uma das dimensões das instituições segundo Scott (1995). A mudança dos significados e sentidos sobre a produção agrícola, sua qualidade, seus riscos e suas contribuições à saúde humana e ecológica, ressaltando a procedência agroecológica, sem uso de agrotóxicos, passou a orientar a percepção de nutricio- 
nistas e cozinheiras e, assim, a alterar seu comportamento, ampliando as sinergias com as propostas da Coofeliz.

As relações sociais, como afirma Scott (1995), são componentes básicos das mudanças institucionais, ou seja, de modificação das "regras do jogo". Foi a partir da conexão entre atores locais que as barganhas em relação ao ato de compra e venda foram possibilitadas. Segundo depoimento de um agricultor integrante da diretoria da Coofeliz:

\begin{abstract}
Só você ver a lei, as regras vêm de lá e simplesmente eles têm que acatar. Mas nós temos que discutir. O que nós temos é produto da agriculta familiar. Se o costume das escolas é servir batata inglesa toda semana, não dá para o agricultor local. A gente produz é inhame. Se na época de laranja querem maçã, não dá pra agricultor daqui não. Eles tiveram que romper com isso. E graças as nossas estratégias deu certo. Agora nossa relação com a escola é muito próxima. Conseguimos adequar o edital a nossa realidade (Agricultor familiar 3).
\end{abstract}

O depoimento indica como as relações sociais podem alterar substancialmente as formalidades impostas no processo, corroborando a afirmativa de Mark Granovetter (1985) de que as instituições são construções sociais, influenciando e sendo influenciadas por redes sociais. Foi diante das interações constituídas para acessar o Pnae que surgiram acordos formais e informais para o cumprimento das obrigações referentes às chamadas públicas para a compra dos alimentos. O papel de cada um na rede foi se modelando a partir das interações e possibilitou, assim, criar soluções e formas de contornar as necessidades e barreiras apresentadas pelo desenho do programa e pelos padrões de exigência em relação aos alimentos.

A Coofeliz também avançou em direção à busca de conformidade normativa, adequando-se a regras que não poderiam ser alteradas e que são impostas por lei, como a adequação sanitária no processamento de alimentos. Para atender as condições impostas pela legislação sanitária, foram oferecidos cursos aos cooperados, abordando formas de manipulação dos alimentos e inspeção sanitária com o objetivo de induzir novas práticas à rotina dos agricultores. A cooperativa terminou a construção de uma agroindústria de minimamente processados, atendendo a todos os padrões legais de produção e ampliando sua capacidade de oferta de produtos com valor agregado. A criação da marca "Chão Feliz" também sinaliza um avanço no processo comercial, garantindo identidade e origem, atendendo a normas de comercialização para fora do município.

Outra estratégia da Coofeliz apontada pela diretoria é a doação de dias de trabalho pelos cooperados à execução dos contratos do Pnae. A cada dia da semana, um 
cooperado envolvido com o programa se dedica a ajudar na organização e entrega dos produtos às escolas. De acordo com os agricultores entrevistados, essa estratégia é importante para diminuir os custos e ampliar o engajamento de quem fornece com quem consome. Além de ajudar na organização dos produtos na cooperativa, há também a visita às escolas para a entrega dos alimentos. A inserção do agricultor no ambiente escolar, por ocasião da entrega dos produtos, cria um ambiente de reconhecimento das regras. Os relatos da presidente confirmam essa questão:

\begin{abstract}
Isso serve para o agricultor entender também que não pode trazer qualquer coisa pra cá, porque, quando chega nas escolas, tem reclamações. Uma forma de ele entender melhor o programa e entender melhor a cooperativa. É bom para os agricultores também entenderem a importância deles estarem na roça produzindo e entregando os produtos porque as crianças ficam felizes (presidente da Coofeliz).
\end{abstract}

Como relatado pela presidente, ao compreenderem a forma como funciona o processo de compra institucional, os agricultores reconhecem as regras criadas pela organização ou impostas por outros agentes do mercado. Outro mecanismo criado pela Coofeliz está intrinsecamente relacionado a um aspecto formal do processo gerencial da cooperativa. Com as entregas para o Pnae, a gestão da organização se tornou mais complexa. Com isso, os diretores criaram, na Cooperativa de Crédito (Cresol), uma conta bancária específica para o Pnae. O depoimento da presidente da Coofeliz relata esse processo:

\footnotetext{
A gente fez uma coisa que foi bacana, pra mexer na parte financeira da cooperativa. Cada movimentação tem uma conta. A conta do Pnae é separada, conta de movimentação, de pagar as contas de dia a dia. Todos os nossos projetos têm suas contas específicas. Tivemos que mexer nisso para não dar bagunça e para ter mais transparência depois também (Presidente Coofeliz).
}

Essas "estratégias" até aqui apresentadas fazem parte das mudanças institucionais induzidas pela implementação de um programa público e sua apropriação pelos atores locais. Essas mudanças institucionais não ocorrem apenas nas práticas sociais, mas também acontecem no âmbito organizacional, como se notou. A complexidade da gestão tem forçado a Coofeliz a profissionalizar a gestão, contando com o apoio de um contador e oferecendo capacitações para diretores, além de criar novas estratégias de interação e engajamento de seu quadro social. Esse contexto gerencial e organizativo induzido pelo Pnae ressoou também na criação de uma importante inovação institucional, necessária para o melhor funcionamento da compra pública de gêneros alimentícios e a fidelização dos cooperados integrados ao Pnae, chamado de "Vale Solidário". 


\section{O Vale Solidário}

Uma das grandes reclamações dos agricultores em relação aos programas de compra governamental é o prazo dos pagamentos. Ao vender para atravessadores e na feira, os recebimentos eram imediatos e, quando se tratava do Programa de Aquisição de Alimentos (PAA), estes demoravam 60 dias e, para o Pnae, em média 30 dias. Diante da inexistência de capital de giro para que a cooperativa pagasse aos agricultores no momento da entrega dos produtos para depois receber do governo, os cooperados precisavam esperar esse pagamento para terem acesso ao valor de suas vendas. Com o intuito de resolver a questão, a Coofeliz criou, em 2010, o Vale Solidário, uma espécie de cheque informal que funciona como moeda social, por meio da qual a cooperativa dava garantias instituFIGURA 1 cionais (de crédito) ao cooVALE SOLIDÁRIO perado. Por meio desse Vale Solidário o cooperado tinha em mãos essa "moeda" com um determinado valor atestado, correspondente ao seu recebimento devido e com isso ele poderia retirar o montante do valor após 30 dias na

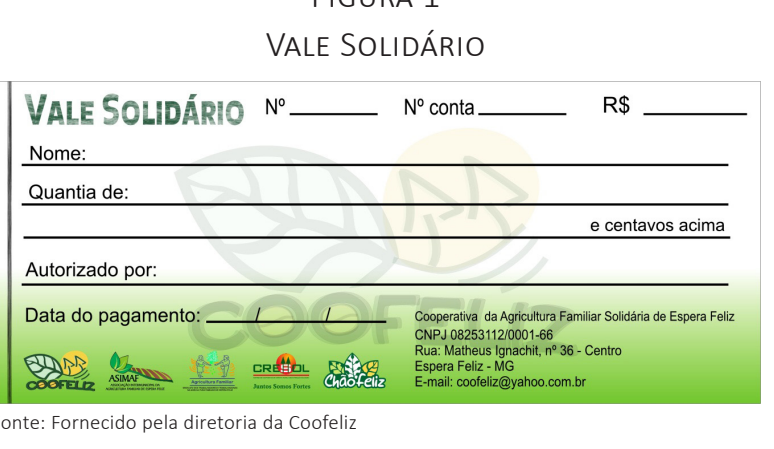
Cresol ou então reverter o valor em compras no mercado local, com comerciantes que foram conveniados à Coofeliz. A Figura 1 mostra o Vale Solidário.

A Coofeliz realizou, então, uma parceria com a Cresol, para que a instituição financeira se responsabilizasse pelas quitações dos Vales Solidários sempre que o montante referente à venda para o Pnae fosse depositado na conta específica. Foi realizada também parceria com comerciantes locais, para que eles aceitassem o Vale Solidário dos agricultores e resgatassem o valor referente em 30 dias. Dessa forma, o Vale Solidário tornou-se um mecanismo de mediação financeira para trocas materiais, tal qual uma moeda social. Os agricultores recebiam o Vale Solidário, poderiam trocar no comercio local, e os comerciantes, resguardando o tempo certo, trocavam na Cresol o Vale Solidário por dinheiro.

Os comerciantes fazem um convênio formal com a cooperativa por meio de um contrato formal, como forma de garantir segurança por parte da cooperativa sobre o funcionamento do Vale Solidário. Os relatos da presidente da cooperativa demostram que a credibilidade da cooperativa no comércio local ativa a confiança no mecanismo. 
Comerciantes ligam pra cá [coofeliz] e falam: "eu tô aqui com o agricultor tal que me entregou um tal de um vale, que parece um cheque. Como é isso? Isso funciona?". A gente fala que pode pegar, que está em número da conta da cooperativa, então a gente passa os nossos dados. Aí a pessoa aceita tranquilamente. Até hoje, nunca tivemos fraudes, nunca tivemos problemas.

O Vale Solidário se institucionalizou como moeda social de circulação local. Segundo depoimentos do Agricultor familiar 1, comerciantes que não são conveniados estão aceitando o vale, proporcionando sua propagação não intencional como moeda social e expandindo seu impacto na dinâmica econômica da agricultura familiar. De acordo com a diretoria, "nós nunca conversamos com os taxistas, mas hoje os taxistas aceitam. Se quiser chegar nesse barzinho, eles aceitam também". A expansão acontece mediante as relações de confiança. Para um comerciante local entrevistado, ele aceita o vale, porque sabe que ele vem de pessoas sérias e que só recebe "de quem tem algum conhecimento, porque o Vale Solidário tem credibilidade na cidade. Não é igual cheque que tem chances de voltar, é garantia".

Para garantir que esse mecanismo funcione, a Cresol criou alguns meios de evitar a falsificação, como a marca d'água e a assinatura direta da presidente da Coofeliz. Contudo, o mecanismo mais importante que viabiliza esse processo é a confiança gerada pelos vínculos entre os indivíduos. Como afirmaram Márcio Silva e Paulo Cesar Amorim Jr. (2013), o vale não é um cheque, mas um valor movimentado entre as duas cooperativas e que tem como lastro as relações de confiança construídas localmente.

Além das formas de credibilidade apresentadas, a Coofeliz também instituiu mecanismos formais com o intuito de garantir que o Vale Solidário não seja um mecanismo passível de falsificações ou frustrações. Os diretores da Coofeliz, na intenção de ampliar o número de comerciantes adeptos a receberem o Vale Solidário, fizeram visitas pessoais aos estabelecimentos comerciais para apresentar o vale, a cooperativa e as parcerias. Cada comerciante era convidado a assinar e, assim, formalizar sua participação nesse processo, recebendo garantias formais do formato de pagamento.

\section{O caso de Guaraciaba}

No município de Guaraciaba, as associações rurais - organizações envolvidas com a entrega de gêneros alimentícios para a alimentação escolar - foram criadas em grande medida pelo incentivo de agentes externos, como a Secretaria de Meio Ambiente e Produção Rural (SMAPR) e a Emater, muitas delas exatamente para este motivo, viabilizando a execução no município e, assim, o trabalho daquelas instituições. Quando questionados sobre o Pnae, os agricultores se referiram ao programa 
citando o nome das representantes do poder público: "o programa da fulana" ou "o programa da prefeitura". Essas questões demonstraram parte do desconhecimento dos agricultores entrevistados sobre o funcionamento do Pnae. Investigou-se como essas associações foram constituídas para relacionar seu processo de criação com a forma com que acessam e se posicionam nas políticas públicas. Os depoimentos sobre a forma de constituição ajudam a explicar a realidade:

O pessoal da Emater dava uma assistência muito boa. Só que aí, ao mesmo tempo que criou várias associações, se resumiu na política. Porque, o que que acontece, se a política parar, infelizmente todas as associações ficam assim meio que sem ter o que fazer (Agricultor familiar 6, Guaraciaba).

Associações aqui foram criadas só para realizar uma compra conjunta; só para acessar um programa. Tem que implorar para ter presidente, todos têm medo. Os associados não fazem nada em conjunto, são atuações muito individuais. A ideia é "tem dinheiro pra associação, vamos criar uma associação". E isso não levou a mobilizações conjuntas. Se a prefeitura tirar o apoio, para tudo (representante da SMAPR).

Os relatos mostram que as associações estão mais vinculadas a oportunidade de acessar recursos e benefícios do que a uma demanda concreta de seus associados e de suas experiências coletivas. A forma imediatista de criação das organizações pode resultar em falta de comprometimento dos associados. Além da referência à comunidade onde moram e a identidade de agricultores familiares, não há o que os integre à ação coletiva e ao funcionamento da organização, tornando-os apenas fornecedores de alimentos, com autonomia reduzida sobre o processo de venda. Por falta de protagonismo dos agricultores em relação às organizações e pelo papel central assumido pela prefeitura - especificamente pela SMAPR e pela Emater-, a forma de operar a compra institucional de alimentos para as escolas ganha contornos particulares. Devido à necessidade de atender à Lei 11.947 e também à oportunidade de incentivar ainda mais a organização social e a produção rural, o poder público local não poupou esforços para colocar na alimentação escolar os produtos locais.

A iniciativa pelo início das compras - segundo relatos do Agricultor familiar 3 - veio da Emater, que começou a incentivar os produtores, juntamente com a SMAPR. Logo, com o início das compras, o poder público contratou uma funcionária para ficar exclusivamente em função de apoiar a compra institucional de alimentos e a Asfag. Essa funcionária - que chamaremos de "Funcionária M" - fica nas dependências da SMAPR, onde também está a Emater. Dessa forma, os atores que centralizam a operacionalização da lei estão sempre em contato uns com os outros. 
Quando se questionou os agricultores sobre quem dita as normas para a entrega dos produtos, as respostas foram sempre "a Funcionária M" ou a "Prefeitura". De acordo com a representante da SMAPR, no início do processo de compra de alimentos da agricultura familiar havia uma forma de disputa por preço, uma licitação, na qual o agricultor que garantisse menor preço ganhava o direito de vender para a merenda escolar. Ao observarem que esta lógica era desfavorável aos agricultores, os representantes da Emater local, em conjunto com a SMAPR, buscaram, na Emater de Viçosa (MG), um curso de capacitação no processo de compra de alimentos da agricultura familiar. Com o curso, ficou claro que não deveria haver concorrência, mas, sim, uma forma conjunta de favorecer a todos. A partir de então, as regras locais de compra mudaram como indica o depoimento a seguir:

\begin{abstract}
Antes da gente ter um treinamento, existia a concorrência entre produtores, o produtor ia lá e o produtor ficava brigando com outro produtor baixando preço, depois [fulana] veio fez um treinamento com a gente com o pessoal da licitação com o pessoal da educação e a gente viu que tava errado a licitação, não é uma licitação que deve ser feita, o produtor não tem que brigar com produtor por causa de preço, nós não estamos ajudando ele se fizer dessa forma. Então entraria a associação e a associação dividiria a entrega pelo número de produtores interessados em entregar (Funcionária M).
\end{abstract}

Nós não estamos ajudando eles [agricultores] se fizer dessa forma. Então, entraria a associação e a associação dividiria a entrega pelo número de produtores interessados em entregar (representante da SMAPR).

Por conta dessa nova configuração na compra, uma agricultora relatou que "antes tinha oportunidade de entregar mais, e agora tem que arrumar outro meio de vender o feijão que não deixam entregar" (Agricultor familiar 5). O relato mostra que a regra foi criada por inspiração de experiências externas, mas adequada à realidade local, embora seja contraditória para muitos dos entrevistados. No entanto, a regra foi aceita e implementada, visto que quem não aceitasse estaria fora da oportunidade de vender por determinação da prefeitura.

Um dos agricultores entrevistados disse que "implora para que a Funcionária M compre a mandioca que está perdendo ou o feijão que não vendeu", mas que ela não pode atender a todas as requisições feitas por ele. Nota-se que a referência à compra é direcionada à Funcionária M. A representação que os agricultores possuem sobre a compra institucional, centralizada na Funcionária M, garante ainda mais legitimidade à atuação da administração municipal, onde qualquer regra imposta está sujeita a ser prontamente acatada por eles. 
A gestão do programa, portanto, é definida e operacionalizada pela prefeitura, com apoio da Emater, por meio da Funcionária M. O papel da associação é marginal nesse processo, como CNPJ necessário ao programa, já que o controle e mediação com os agricultores no âmbito da execução do Pnae é de sua responsabilidade. Uma forma de controle das entregas, estabelecida pela Funcionária $M$, é uma medida "para que ninguém esqueça que precisa entregar seus produtos". Conforme relatos do Agricultor Familiar 3:

Ela [funcionária M] já marca os dias de entrega, ela manda aquele papelzinho pra gente colar na geladeira e não esquecer. O que chega são os dias de entrega e o que que a gente vai entregar. Ela manda por e-mail, mas igual, por exemplo, quem não tem internet na zona rural, ela manda cartinha mesmo, o bilhetinho mesmo (Agricultor Familiar 3).

Para a Funcionária $\mathrm{M}$, mandar um calendário indicando os dias das remessas e os produtos a serem entregues tem sido importante para que haja mais assiduidade por parte dos agricultores. É uma tentativa de mudar o comportamento. Esse planejamento também é feito pela SMAPR e pela Emater durante reunião com os agricultores, onde se faz o levantamento das disponibilidades destes em função das demandas das escolas. O planejamento é igualmente elaborado por esses atores e repassados aos agricultores.

Estas formas de controlar o comportamento por meio da exposição do planejamento foi acentuado quando começou a aparecer os primeiros problemas relacionados a regularidade das estregas dos alimentos nas escolas. O depoimento a seguir relata a questão:

Aí começou as escolas reclamando, a secretaria da educação reclamando. Eu falei assim, "oh gente, então vamos fazer o seguinte, vamos reunir todo mundo e perguntar: e aí, com quem não traz, o que vai acontecer? Eu sei que todo mundo tá sujeito a um carro estragar, todo mudo tá sujeito a dar uma tempestade e acabar com tudo na horta! Mas teríamos que fazer alguma coisa. E aí as escolas começam a pedir menos coisa, por quê? Porque o sacolão não atrasa, o mercado entrega tudo no dia que está marcado, e dá nove horas, dez horas, a merenda tem que sair. Então a gente vai perdendo coisa que a gente podia vender, uma pasta de alho, coisa que eu insisto pra colocar mais, que o produtor faz e que eles compram do mercado. Na hora que eu vou falar com o pessoa das escolas que eles poderiam comprar mais coisas dos produtores eles me respondem assim, "pra que que eu vou comprar mais coisa?, eles não entregam!' Aí chamamos todo mundo pra uma reunião e colocamos: e aí fica por isso mesmo, o que que acontece 
com quem não entrega? Aí todo mundo falou: não participa mais! Tem que ter uma punição até mesmo pra você educar o produtor, porque senão ele vai continuar. Entendeu?"

O depoimento mostra o processo pelo qual surgiu a necessidade de construção de uma regra para atender outra regra imposta pela dinâmica do programa. O atendimento com regularidade impõe que os agricultores tenham uma rotina planejada. A regra criada é um dispositivo institucional que garante um sistema de punição ao agricultor que infringir a norma, concebido pelo ator que determina como deve funcionar a execução local do programa. As punições e sanções foram edificadas sobre comportamentos inadequados ao modelo de gestão exercício pela prefeitura e que comprometeram a imagem da compra institucional de alimentos no município. Nesse caso, a legitimidade do mercado institucional é construída a partir do poder exercício pelo dos atores relacionados a SMAPR e Emater.

No início das entregas, os representantes dos gestores escolares de duas escolas relataram que não havia nenhuma preocupação com a qualidade dos produtos, além da ocorrência de outros problemas no recebimento. Essas afirmativas também são confirmadas no depoimento que se segue:

\footnotetext{
Antes eles entregavam nas escolas, pegavam uns $30 \mathrm{~km}$ de terra pra deixar na escola. O produtor deixava lá e ia embora. E a cantineira é que dava o aval. Não tinha controle. Pra secretaria de educação era muito cômodo. Mas depois foi dia e horário marcado na cidade, com a nutricionista avaliando. Depois a prefeitura entrega. Eles ganharam em logística e a prefeitura em controle (SMAPR, Guaraciaba).
}

Os gestores escolares, diante dos problemas ocasionados pela falta de critérios, começaram, então, a descredibilizar e a reclamar das entregas dos produtos da agricultura familiar, suscitando em necessidade de reformulação das regras. As regras de padronização da qualidade surgiram por exigência dos diretores de escolas ao notarem a falta de conformidade e controle sobre os produtos e pela percepção da SMAPR de que era necessário mudar para não perder a oportunidade.

Devido à falta de controle da qualidade, mudou-se a função da nutricionista e se retirou da cantineira a função do controle. Padrões de controle foram adotados e isso também implicou em mudança de comportamento dos agricultores que "faziam tudo do seu jeito". Revela-se, no depoimento, que as mudanças institucionais ocorrem em todos os âmbitos do Pnae, no sentido de aprimorar os processos que operacionalizam o programa. 


\section{Análise das mudanças institucionais}

Por meio do conhecimento dos processos acima relatados, é perceptível que as regras do Pnae provocaram impactos nas formas como os agricultores produziam, se organizavam e interagiam. Diversas variáveis influenciaram a intensidade e a forma como as regras - formais e informais - foram criadas ou modificadas. Em Guaraciaba, pela posição marginal dos agricultores, as regras eram definidas pela funcionária cedida pela prefeitura e apenas legitimadas pelos agricultores.

Mas, de toda forma, os casos mostram que a organização dos agricultores precisa ser vista como "verbo" (ato de organizar) e não apenas como "substantivo", uma vez que não pode significar apenas um espaço físico ou um CNPJ pelo qual uma operação de venda acontece. Há nos casos um olhar coletivo sobre a implementação. Isso é confirmado pelo dispositivo de punição surgido em Guaraciaba para que todos possam entregar sem gerar problemas, e em Espera Feliz pela experiência de troca de dias de serviço e de doação do tempo de trabalho.

A ausência de cooperação implicava em riscos, e o controle só é efetivo se os atores interiorizarem os elementos morais pressupostos na colaboração entre eles, ou seja, à medida que se institucionalizam as regras. Existem sanções pela conduta "desviante", mas elas só funcionam, como afirmou Nan Lin (2001), pela presença de recursos morais que têm a virtude de aumentar conforme seu uso e dos quais a confiança é o mais importante.

As mudanças institucionais não se restringiram aos agricultores. Todos os atores envolvidos precisam adequar comportamentos ou mudar formas de pensar o processo. O poder público precisou adequar todo o processo de compras dos alimentos da merenda escolar, rompendo com o modo antigo, baseado na compra a partir de licitação, realizadas com grandes varejistas capazes de concorrer com preços mais baixos. As nutricionistas das prefeituras também precisaram se adequar e mudar as funções, centrando seu olhar e atenção para os agricultores familiares. As escolas também vivenciaram mudanças institucionais, passando por adaptações em todo o processo de elaboração e oferta da alimentação escolar, bem como na compreensão da própria alimentação no cotidiano escolar.

A mudança de interpretação sobre a qualidade dos alimentos levou as cozinheiras das escolas a aceitarem produtos de qualidade diferente dos tradicionais e a substituir alguns produtos por outros produzidos localmente. A princípio, a aceitação dos produtos locais revelou conflitos, mas o processo de interação levou à mudança institucional. Os agricultores relataram que as escolas aceitam que produtos que 
estavam previstos para serem entregues pudessem ser eventualmente substituídos por outros. Diante dessa situação, a nutricionista ou a diretora da escola aceitaram substituir por outro produto, o que é permitido por lei, mas que localmente se negocia e se definem os termos que orientaram esse processo. Isso demonstra que elementos informais auxiliam no funcionamento das instituições do programa.

Os casos apresentam como os agricultores estão condicionados às regras da legislação sanitária e que não reflete as formas como as famílias e os atores sociais locais interpretam as atividades de processamento de alimentos. As regras construídas não são deslocadas da ação individual, elas são enraizadas socialmente. Os dispositivos institucionais surgiram das próprias interações, mas também as influenciaram reciprocamente.

As diferentes realidades operativas do Pnae em Guaraciaba e em Espera Feliz foram traduzidas nitidamente por consequência das redes sociais edificadas ao processo. A natureza dessas relações - como mostrado - traduz-se em formas diferentes de estruturas sociais. Em Guaraciaba, a associação central assumiu papel de expectadores e são marginais na rede. Em Espera Feliz, a Coofeliz assumiu papel de protagonista e centralidade na rede. Esses papéis e posicionamentos configuram processos políticos distintos, que particularizam as dinâmicas locais de implementação do Pnae.

Para Cécile Raud-Mattedi (2005), as instituições, bem como os significados que elas imprimem a um determinado grupo ao orientar seu comportamento, são condicionadas pelos conteúdos e pela estrutura das relações sociais na qual esse grupo está imerso. Logo, a rede, seu formato e seu enraizamento social, condiciona a forma como as instituições são edificadas ou adaptadas. Os casos revelam que os acordos criados e os dispositivos institucionais mostrados foram edificados a partir do interesse daqueles atores que assumiram posições centrais na rede.

Essa importante afirmativa leva a compreender que a experiência do Vale Solidário, por exemplo, teria dificuldades de emergir no contexto de Guaraciaba, pois a centralidade da rede está na SMAPR e Emater, e os agricultores apenas ocupam posições marginais na rede. Conforme se pode notar, em Guaraciaba as regras de funcionamento do mercado são criadas pelos atores do poder público e acordadas pelos agricultores.

A rede em torno do mercado institucional se institucionaliza, modelando um formato próprio às ações, com regras compartilhadas. De acordo com Scott (1995), a institucionalização é um processo social pelo qual os indivíduos passam a compar- 
tilhar uma realidade social. Dessa forma, as regras criadas condicionam o comportamento, mas as interações sociais modificam essas institucionalidades. Assim, elas não podem ser consideradas imutáveis ou reificadas.

No caso de Espera Feliz, é mister notar que há flexibilização das regras formais impostas pelo edital de compra dos alimentos criado pela Secretaria de Educação. Tal fato ocorre mediante o diálogo e a relação de confiança construída entre os atores envolvidos nesse processo. A confiança, que levou à flexibilização, é um mecanismo institucional necessário na mediação dos acordos. Para Granovetter (1985), a fonte de confiança nas relações sociais reside na preferência generalizada dos indivíduos em estabelecer transações com pessoas e organizações de reconhecida reputação. A reputação da Coofeliz no município de Espera Feliz fez com que os dirigentes escolares tivessem mais confiança na organização coletiva e na qualidade do produto entregue. Esse caso específico mostra que a rede, além de movimentar um fluxo de informação, também é responsável pela difusão da reputação, assegurando as relações de confiança.

A reputação da Coofeliz influenciou diretamente a percepção do risco de flexibilizar as normas, promovendo relações de confiança que influenciaram os níveis de cooperação. A construção dos acordos informais com a secretaria de educação esteve, assim, associada à legitimidade dos atores no campo e prescindiu que atores com maiores habilidades sociais (Flingstein, 2007) pudessem buscar cooperação em seus propósitos, que se tornam mediadores na construção dos mecanismos institucionais, assim como foi com o Vale Solidário.

Os seminários locais promovidos em Espera Feliz trouxeram maior legitimidade à produção sem agrotóxico e à Coofeliz. Para Mark Suchman (1995), a legitimidade incorpora uma dimensão cognitiva e explicita o papel do reconhecimento social. Esse reconhecimento, além de gerar a confiança necessária para estabelecer as transações, edifica uma reputação que favorece a credibilidade no papel central assumido pela cooperativa.

A representação social que os agricultores entrevistados em Guaraciaba possuem a respeito do programa interfere no modo como encaram as regras. Ao identificarem o Pnae como "programa da Funcionária M", "Programa da Prefeitura" ou "Programa da Emater", os agricultores apenas esperam que as regras sejam criadas e assumem uma postura passiva nessa relação com atores do poder público.

Como registrado em caderno de campo sobre a experiência de Espera Feliz, o ingresso na cooperativa e nessa rede acaba sendo feito por indicação. As indicações 
servem como forma de controle e manutenção da estabilidade, uma vez que a indicação incumbe quem indica de responsabilidade sobre o indicado. A transmissão da responsabilidade e da confiança acontece pelo fato de um cooperado confiar em $X$, porque $Y$, que ele conhece e confia, confia nesse indivíduo $X$. Dessa forma, estabelecem-se relações de confiança baseadas na reputação e nos vínculos anteriores, expressando a transitividades das redes sociais. A pessoa que indica, por sua vez, para manter sua reputação, não indica quem ela não confia de fato, para não arriscar. Logo, há a reprodução das relações de confiança, o que facilita a cooperação.

A cooperação vista como elemento institucional presente implementação do Pnae é identificada na doação de dias de serviço, conforme relatado no caso de Espera Feliz. Negar-se a contribuir com a cooperativa seria o mesmo que negar contribuir com os outros que colaboram, além de arcar com as sanções legais que poderia haver, como ter cerceado o direito de vender e sofrer sanções morais. Essa experiência também funciona como instrumento de geração de legitimidade das regras e do funcionamento do mercado institucional pelos agricultores.

Os dois casos descritos neste trabalho, além de revelarem a importância da análise institucional, contribuem para operacionalizar a noção do enraizamento social, explicitando como a imersão dos atores nas relações sociais interfere em suas intervenções. Essa imersão implica na formação de representações sociais, as quais direcionam os comportamentos dos atores, uma vez que são mediadoras de suas ações. O argumento da imersão levantado por Granovetter (1985) enfatiza o papel das relações pessoais concretas na origem da confiança e no desencorajamento da má-fé. Granovetter (1985) sustenta que as relações sociais, mais do que dispositivos institucionais, são as principais responsáveis pela produção de confiança na vida econômica.

Toda dimensão institucional elucidada neste trabalho mostra que a forma de operacionalização do Pnae é diferente de acordo com o contexto, porque há configurações sociais distintas e, assim, arranjos institucionais diferentes. Os contextos sociopolíticos e organizativos influenciam, edificando, a partir das relações sociais, normas que se adequam às realidades sociais e culturais locais. A inserção na lógica da compra institucional exige dos agricultores locais a submissão às regras preestabelecidas. Por sua vez, é necessário o aprendizado coletivo sobre como se adequar às exigências. Contudo, isso não impede que regras paralelas e informais sejam adotadas pelo grupo, seja para atender às normas legais do programa, seja para contornar alguma barreira imposta no processo. 


\section{Conclusão}

Ainda que o desenho institucional do Pnae determine as diretrizes básicas, especialmente objetivos e metas que deverão ser alcançadas, conclui-se que são as interações locais e os acordos construídos por meio delas que conduzirão a implementação da política pública, articulando as regras do programa aos interesses dos atores locais e aos dispositivos institucionais que eles criam. Isso indica, portanto, que a implementação da compra institucional de alimentos é regida pelas regras criadas localmente e, em conjunto com as regras impostas pelo Estado, conformam-se dinâmicas próprias ao programa, como explicitou as particularidades e distinções entre os casos de Guaraciaba e Espera Feliz. Essas referências normativas são acordadas coletivamente, legitimadas pelos atores, influenciam suas representações sociais e, assim, suas intervenções nos processos locais de implementação.

As mudanças institucionais induzidas localmente são essenciais para que as políticas públicas possam ser ajustadas ao contexto social e às práticas cotidianas dos atores que se envolvem em sua implementação. Essa análise destaca a habilidade de alguns atores em estabelecer regras e construir recompensas e sanções que sustentam a ordem e a coerência intencionada para o processo. Na análise da implementação do Pnae aqui empreendida, conclui-se que em contextos nos quais as organizações da agricultura familiar apresentam trajetórias político-organizativas de luta por direitos, a partir de mobilizações sociais e de processos cooperativos, a compra governamental de alimentos se torna instrumento de fortalecimento organizativo e empoderamento, alçando a agricultura familiar como protagonistas da construção social da política, ampliando sua capacidade mobilizadora e a inovação, como foi o caso de Espera Feliz.

Pode-se afirmar, conclusivamente, que é por meio da ação dos indivíduos, no processo de interação, que a mudança institucional acontece. É por meio das relações sociais e das negociações que emergem novas regras e novos acordos que ajudam a regular os comportamentos e a modelar a forma como o Pnae é executado na prática. Vale observar que o surgimento de inovações institucionais - como o Vale Solidário - não estava previsto pelos formuladores do programa. Novas rotinas foram criadas para apreender a forma de operar a venda para a alimentação escolar.

Não se pretendeu aqui emitir juízos de valor sobre qual a melhor forma de implementar o Pnae ou definir qual a experiência mais significativa, pois, apesar da grande distinção das configurações sociais e institucionais dos casos aqui analisados, ambos contribuíram para a geração de renda das famílias rurais e para a inserção de alimentos frescos e saudáveis à rotina alimentar das escolas. Para além de 
qualquer julgamento de mérito, a pesquisa contribuiu para revelar como o Pnae é apropriado localmente e contextualizado à dinâmica das interações sociais, à forma como as redes sociais locais estão constituídas, mas também que isso ressoa de forma diferente sobre o papel dos atores e suas ações, gerando consequências que extrapolam a transação econômica de compra e venda de alimentos, revelando uma dimensão institucional dos processos locais de implementação da política pública.

Os dispositivos institucionais criados para viabilizar a operacionalização do programa e adaptá-lo ao contexto local e os processos dos quais eles derivam podem habilitar ou constranger o envolvimento dos agricultores familiares e seu protagonismo, repercutindo em diferentes graus de autonomia e alienação na relação entre sociedade e Estado.

Conclui-se, assim, que a implementação dessa política pública pressupõe a interdependência entre os diferentes atores locais, sendo a configuração das redes sociais a chave explicativa dos contornos institucionais e resultados específicos gerados.

\section{Referências}

ABREU, Kate D. R. A implementação do Programa Nacional de Alimentação Escolar (Pnae) em municípios de pequeno porte: implicações práticas e teóricas. Dissertação (Mestrado) - Fundação Getúlio Vargas, São Paulo (SP) 2014.

ARRETCHE, Marta. A agenda institucional. Revista Brasileira de Ciências Sociais, v. 22, n. 64, p. 147-151, 2007.

BRASIL. FNDE. Programa Nacional de Alimentação Escolar (Pnae) - Apresentação. 2014. Disponível em: <http://www.fnde.gov.br/index.php/programas/alimentacao-escolar/alimentacaoescolar-apresentacao>. Acesso em: 25 Nov. 2019.

DIMAGGIO, J. Paul; POWELL, W. Walter. A gaiola de ferro revisitada: isomorfismo institucional e racionalidade coletiva nos campos organizacionais. Revista de Administração de Empresas, v. 45, n. 2, p. 74-89, Abr./Jun. 2005.

FLIGSTEIN, Neil. Habilidade social e a teoria dos campos. RAE - Revista de Administração de Empresas, v. 47, n. 2, p. 61-80, 2007.

FREITAS, Alair. F. Dinâmicas sociais e desenvolvimento territorial no território Serra do Brigadeiro: atores, redes e instituições. Tese (Doutorado em Administração) Centro de Pós-graduação e Pesquisas em Administração (Cepead) da Universidade Federal de Minas Gerais (UFMG), Belo Horizonte (MG), 2015. 
GIL, Antônio C. Métodos e técnicas de pesquisa social. 6 ed. São Paulo: Atlas, 2010. GRANOVETTER, Mark. Economic action and social structure: the problem of embeddedness. American Journal of Sociology. v. 91, n. 3, p. 481-510, 1985.

GRISA, Cátia. Políticas públicas para a agricultura familiar no Brasil: produção e institucionalização das ideias. Tese (Doutorado em Ciências Sociais) - Programa de Pós-graduação de Ciências Sociais em Desenvolvimento, Agricultura e Sociedade/ Universidade Federal Rural do Rio de Janeiro (UFRRJ), Rio de Janeiro (RJ), 2012.

HALL, Peter. A.; TAYLOR, Rosemary. C. R. As três versões do neo-institucionalismo. Lua Nova, n. 58, p. 193-223, 2003.

INSTITUTO BRASILEIRO DE GEOGRAFIA E ESTATÍstICA (IBGE). Censo Agropecuário 2006. Disponível em: <http://www.sidra.ibge.gov.br>. Acessado em: 15 Mar. 2015.

KIRSCHBAUM, Charles. Elementos para uma teoria institucional intra-organizacional. Perspectivas Contemporâneas, Edição Especial, p. 5-21, 2010. Disponível em: $<$ http://revista.grupointegrado.br/revista/index.php/perspectivascontemporaneas/article/view/903/314>. Acessado em 02 Mar. 2018.

KLIJN, Erik-Hans. Analyzing and managing policy processes in complex networks: a theoretical examination of the concept policy network and its problems. Administration and Society. Sage Publications, v. 28, n. 1, May 1996.

LAVILLE, Christian.; DIONNE, Jean. A construção do saber. Belo Horizonte: Editora UFMG, 1999.

LIN, Nan. Social capital: theory of social structure and action. Cambridge: Cambridge University Press, 2001

LOTTA. Gabriela S. Implementação de políticas públicas: o impacto dos fatores relacionais e organizacionais sobre a atuação dos burocratas de nível de rua no Programa Saúde da Família. Tese (Doutorado) - Departamento de Ciência Política, Universidade de São Paulo (USP), São Paulo (SP), 2010.

MARQUES, Eduardo. C. L. Redes sociais, instituições e atores políticos no governo da cidade de São Paulo. São Paulo: Anablume; Fapesp, 2003.

NORTH, Douglas. C. Institutions, institutional change and economic performance. Cambridge: Cambridge University Press, 1990. 
PEARSON, Paul. Politics in time: history, institutions and social analysis. Princeton: Princeton University Press, 2004.

RAUD-MATTEDI, Cécile. Análise crítica da sociologia econômica de Mark Granovetter: os limites de uma leitura do mercado em termos de redes e imbricação. Política \& Sociedade, n. 6, p. 59-82, 2005.

ROCHA, Roberto. A avaliação da implementação de políticas públicas a partir da perspectiva neo-institucional: avanços e validade. Cadernos Ebape.BR,v. 2, n. 1, p. 1-12, 2004.

ROLAND, Gérard. Understanding institutional change: fast-moving anda slow moving intitutions. Studies in comparative international development. Providence, v. 38, n. 4 , p.109-131, 2004.

SCOTT, Willian. R. Institutions and organizations. London: Sage Publication, 1995.

SILVA, Marcelo Kunrath; SCHMITT, Cláudia Job . As organizações sociais e o Programa de Aquisição de Alimentos no Rio Grande do Sul. In: MARX, Vanessa. (Org.). Democracia participativa, sociedade civil e território. Porto Alegre: Editora UFRGS; CEGOV, 2014.

SILVA, Márcio G. Políticas públicas de desenvolvimento rural e organizações da agricultura familiar em Espera Feliz. Dissertação (Mestrado) - Universidade Federal de Viçosa, Viçosa, Minas Gerais, 2010.

SILVA, Márcio G. ; AMORIM JUNIOR, Paulo Cesar. Inovações organizacionais para a construção de mercados locais e solidários em Espera Feliz (MG). Revista Agriculturas, v. 10, p. 14-17, 2013.

SUCHMAN, Mark C. Managing legitimacy: strategic and institutional approaches. Academy Management Review, v. 20, n. 3, p. 571-560, Jul. 1995. 